\title{
European Resuscitation Council Guidelines for Resuscitation 2015 Section 11. The ethics of resuscitation and end-of-life decisions
}

\author{
Leo L. Bossaert ${ }^{\mathrm{a}, *}$, Gavin D. Perkins ${ }^{\mathrm{b}, \mathrm{c}}$, Helen Askitopoulou ${ }^{\mathrm{d}, \mathrm{e}}$, Violetta I. Raffay ${ }^{\mathrm{f}}$, \\ Robert Greif $^{g}$, Kirstie L. Haywood ${ }^{\text {h }}$, Spyros D. Mentzelopoulos ${ }^{i}$, Jerry P. Nolan ${ }^{j}$, \\ Patrick Van de Voorde ${ }^{k, l}$, Theodoros T. Xanthos ${ }^{\mathrm{m}, \mathrm{n}}$, on behalf of The ethics of \\ resuscitation and end-of-life decisions section Collaborators ${ }^{1}$
}

\footnotetext{
aniversity of Antwerp, Antwerp, Belgium

${ }^{\mathrm{b}}$ Warwick Medical School, University of Warwick, Coventry, UK

c Critical Care Unit, Heart of England NHS Foundation Trust, Birmingham, UK

d Medical School, University of Crete, Heraklion, Greece

${ }^{\mathrm{e}}$ Ethics Committee of the European Society for Emergency Medicine (EUSEM), UK

${ }^{\mathrm{f}}$ Municipal Institute for Emergency Medicine Novi Sad, Novi Sad, Serbia

${ }^{g}$ University Hospital Bern and University of Bern, Bern, Switzerland

${ }^{\mathrm{h}}$ Royal College of Nursing Research Institute, Warwick Medical School, University of Warwick, Coventry, UK

${ }^{i}$ University of Athens Medical School, Athens, Greece

j Department of Anaesthesia and Intensive Care Medicine, Royal United Hospital, and University of Bristol, Bath, UK

$\mathrm{k}$ University Hospital and University Ghent, Belgium

${ }^{1}$ Federal Department Health, Belgium

m University of Athens, Medical School, Greece

${ }^{\mathrm{n}}$ Midwestern University, Chicago, USA
}

\section{Summary of changes since the ERC 2010 guidelines}

The traditional medical-centred approach with an emphasis on beneficence has shifted towards a balanced patient-centred approach with greater emphasis on patient autonomy. This has resulted in a readiness for understanding and interaction between patient and healthcare professionals. Future guidelines may benefit from involvement of all stakeholders: members of the public, patients, survivors and the society as active partners in understanding and implementing the ethical principles.

The content and implementation of the traditional ethical principles are placed in the context of a patient-centred approach to resuscitation:

- Autonomy, including respect for personal preferences expressed in advance directives, which implies correct information and communication.

- Beneficence, including prognostication, when to start, futility, ongoing CPR during transportation, special situations, with clear distinction between sudden cardiac arrest and expected cessation of cardiac function and respiration in terminal situations.

\footnotetext{
* Corresponding author.

E-mail addresses: leo.bossaert@erc.edu, leo.bossaert@gmail.com (L.L. Bossaert).

1 The members of The ethics of resuscitation and end-of-life decisions section Collaborators are listed in the Collaborators section.
}

- Non-maleficence, including DNAR/DNACPR, when to stop/ withhold and involvement of patient or proxy.

- Justice and equal access, including avoiding inequalities.

Whilst the sad reality is that the majority of those that sustain a cardiac arrest do not survive, recent studies provide evidence of steady improvement in outcomes particularly where the formula of survival is well implemented. Specific cases of refractory cardiac arrest, which would historically have been fatal, may benefit from additional interventional approaches. A further improvement in survival may be expected by applying clear guidance for starting, not starting, withdrawing or withholding resuscitation attempts, and by identifying refractory cases that may respond to advanced interventions.

Europe is a patchwork of 47 countries (Council of Europe) with differences in national laws, jurisdiction, culture, religion, and economic capabilities. European countries interpret the ethical recommendations of resuscitation in the context of these factors.

A survey of current ethical practice across Europe was conducted in the context of these guidelines. A significant variability in the approach to cardiopulmonary resuscitation (CPR) and end-of-life was documented. Whilst areas for improvement were identified, it highlighted a trend towards better application of ethical principles.

The need for harmonisation in legislation, jurisdiction, terminology and practice remains. The mission of the ERC and its Guidelines is to contribute to this harmonisation. 
New European Union (EU) regulation permitting deferred consent will harmonise and foster research of emergency interventions across EU Member States.

Healthcare professionals are responsible for maintaining their knowledge, understanding and skills, and to understand the ethical principles before being involved in a real situation where resuscitation decisions must be made.

\section{Introduction}

Sudden unexpected cardiac arrest (CA) is a catastrophic unexpected but potentially reversible event that involves family, friends and society. In Europe cardiac arrest occurs in $0.5-1.0$ per 1000 inhabitants per year. Although a slow improvement has been observed over recent years, survival after out-of-hospital Cardiac Arrest (OHCA) remains low with an average survival to hospital discharge of $7.6 \% .^{1-9}$

Potentially reversible sudden unexpected cardiac arrest should be distinguished from the expected cessation of circulation and respiration in a terminal condition. Better medical knowledge, new and advanced interventions, and increasing expectations of the public have rendered ethical considerations an important part of any end-of-life intervention or decision. This includes optimising results for individual patients and society by appropriate allocation of resources.

In recent years there has been a shift from a doctor-centred approach with emphasis on beneficence, towards a patient-centred approach with greater emphasis on patient autonomy. This change is reflected in the 2015 ERC ethics guidelines for resuscitation and end-of-life decisions.

This chapter provides information and guidance on the principles of ethics: ethical and professional guidance for healthcare professionals responsible for providing resuscitation including when to start and when to stop resuscitation and special considerations required for children and for organ donation after an unsuccessful resuscitation attempt.

The healthcare professional should understand the ethical principles before being involved in a real situation where resuscitation decisions must be made.

We also report the initial findings from a European survey on Ethical Practices, which documented significant variation between countries in the approach to cardiopulmonary resuscitation (CPR) and end-of-life practices.

There is a clear need for harmonisation in legislation, terminology and practice. The mission of the ERC Guidelines is to contribute to this harmonisation.

\section{Aspects of ethics for resuscitation and end-of-life decisions}

Ethics is defined as the ways of examining and understanding the moral life, or the application of ethical reasoning to medical decision making. The key principles of medical ethics are: autonomy of the individual, beneficence, non-maleficence and justice. Dignity and honesty are frequently added as essential elements of ethics. ${ }^{11-13}$

\section{The principle of patient autonomy}

Respect for autonomy refers to a physician's obligation to respect a patient's preferences and to make decisions that accord with a patient's values and beliefs. Patient-centred healthcare places the patient at the centre of the decision-making process, rather than as a recipient of a medical decision. This requires patients to have an adequate understanding of relevant issues regarding their treatment options, thus enabling them to make informed decisions or participate in shared decision-making. Patient education has contributed significantly to this change in emphasis. The principle of autonomy is implemented through free and informed consent, and recognises that the person may change their decision at any time. Applying this principle during cardiac arrest where the patient is often unable to communicate preferences is challenging. ${ }^{11,14-16}$ Moreover, the legally documented wishes of an individual patient may not be readily available, causing further ethical dilemma: how can healthcare professionals embrace patient-centricity when the views of the patient are unknown? ${ }^{11,17-19}$

\section{The principle of beneficence}

Beneficence implies that interventions must benefit the patient after assessing relevant risk and benefit. Evidence-based clinical guidelines exist to assist healthcare professionals in deciding which treatment approaches are most appropriate. ${ }^{20-22}$ Increasingly, patients are involved as active partners in the guideline development process, ensuring that patient's views and perspective are captured in the guidance provided. ${ }^{23}$ Such involvement, however, has not yet been witnessed in the context of resuscitation guidelines.

\section{The principle of non-maleficence}

Non-maleficence or 'primum non nocere' stems from the Hippocratic axiom 'help or at least do no harm'. CPR should not be performed in futile cases. However, it is difficult to define futility in a way that is precise, prospective and applies to the majority of cases. CPR is an invasive procedure with a low likelihood of success. Advance directives are rarely available to emergency healthcare professionals. Therefore, CPR has become the norm for most patients with acute, life-threatening conditions. ${ }^{24,25}$

\section{The principle of justice and equitable access}

Justice implies that health resources are distributed equally and fairly, irrespective of the patient's social status, in the absence of discrimination, with the right for each individual to receive the current standard of care. The appropriate allocation of resources has become an important consideration for invasive procedures. CPR is a procedure requiring coordinated efforts of many healthcare professionals. The ethical considerations regarding CPR and end-oflife decisions include achieving the best results for the individual patient, for relatives and for society as a whole by appropriate allocation of available resources. There is no consensus about what constitutes a just and fair method of balancing the preferences and requirements of individual patients against the diverse needs of society. ${ }^{11,13,19,21,26}$

Withholding specific medical care due to financial motives is not acceptable but it may be appropriate to consider the overall costs and potential benefits to the individual patient, the family and society. ${ }^{13,21,27-29}$

There is evidence that citizens from lower socioeconomic groups have both an increased incidence and lower chance of survival of OHCA. The likelihood of a person receiving bystander CPR after a cardiac arrest is nearly five times greater in higher income neighbourhoods compared with lower income ones. Caucasian patients are more likely to receive bystander CPR than other ethnic groups. $2,30-39$

\section{Medical futility}

The World Medical Association (WMA) defines futile medical treatment as a treatment that "offers no reasonable hope of recovery or improvement" or from which "the patient is permanently unable to experience any benefit". Resuscitation is considered futile when the chances of good quality survival are minimal. ${ }^{40}$ The first prerequisite to consider a treatment futile is the presence or absence of a medical indication. The decision not to attempt resuscitation does not require the consent of patients or of those close 
to them, who often have unrealistic expectations about the likely success and potential benefits of resuscitation. ${ }^{41,42}$ Starting a futile treatment may offer false hope to the family and patient that may undermine the patient's ability for rational judgment and autonomy. ${ }^{40,43}$ However, decision makers have a duty to consult the patient or a representative if the patient lacks capacity, in accordance with a "clear and accessible policy". ${ }^{44-46}$ The medical team must explain that the decision not to attempt resuscitation does not mean giving up or that the patient will be ignored or abandoned, but rather that the intent is to protect the patient from harm and to maximise comfort and quality of life. ${ }^{44,47}$

Some countries allow prospective decisions to withhold CPR whilst in others countries or religions withholding CPR is not allowed or considered illegal. There is a lack of consistency in terms such as 'Do Not Attempt Resuscitation' (DNAR), 'Do Not Attempt Cardiopulmonary Resuscitation' (DNACPR) or 'Allow Natural Death' (AND). This confusing use of acronyms may generate misunderstandings in national legislation and jurisdiction 48,49

\section{Advance directives}

Advance directives are decisions about treatment provided prospectively by an individual in case they are unable to participate directly in medical decision-making at some point in the future. ${ }^{50}$ Advance directives can take two different but not mutually exclusive forms: (1) 'Living Wills' are written documents that express a person's preferences regarding the provision or the withholding of specified treatments in the event that they become unable to make decisions in the future; and (2) a 'Lasting power of attorney for health care' allows individuals to appoint a proxy (e.g., a trusted relative or friend) who can make health care decisions on their behalf in case they lose decision-making capacity. ${ }^{51}$

The advance directives must meet three criteria: existence, validity and applicability. Physicians must not delay resuscitation interventions while trying to establish if an advance directive prohibiting CPR exists. ${ }^{51}$ Neither must CPR be attempted if it is considered more harmful than helpful, even if contrary to a valid and applicable advance decision.

In several countries advance directives have the same legal force as contemporaneous decisions. However, their applicability is complicated by the challenge of drafting a directive that accurately represents a patient's wishes at the time of writing. ${ }^{52}$ Indeed, people often adapt to disabilities, and preferences may change over time. Therefore, periodic reviews of directives are required to ensure patients' current wishes and circumstances are accurately reflected. $41,52,53$

Article 9 of the Convention on Human Rights and Biomedicine requires physicians to "take into account" previously expressed wishes of their patients. ${ }^{19}$ However, the legal status of advance directives in the national legislation of European countries is very disparate. Several countries have adopted specific laws assigning binding force to advance directives about end of life decisions, including resuscitation. ${ }^{51}$

\section{Human Rights relevant to resuscitation and end-of-life decisions}

Policies about resuscitation and individual decisions of healthcare professionals must comply with human rights. Provisions relevant to decisions about attempting CPR include the following rights: to life; to protection from inhuman or degrading treatment; to respect for privacy and family life; to freedom of expression, which includes the right to hold opinions and to receive information; and to be free from discriminatory practice in respect of these rights. ${ }^{19}$ Failing to involve a patient at the time of writing a DNAR order breaches Article 8 of the European Convention of Human Rights. ${ }^{45}$

\section{Patient-centred care}

The increasing centricity of the patient within healthcare demands that we seek to understand the perspective of the survivor of cardiac arrest, with assessment seeking to be inclusive of clinical and patient-reported outcomes over the short and longer-term. This has been recognised within the updated Utstein Resuscitation Registry template for out-of-hospital cardiac arrest, which recommends the assessment of patient-reported outcomes and the quality of life of survivors. ${ }^{54}$ However, specific assessment guidance does not currently exist. The COSCA (Core Outcome Set-Cardiac Arrest) initiative will seek international consensus on what should be measured and when in all clinical trials of cardiac arrest, and make recommendations on both clinical and patient-reported outcomes. ${ }^{55,56}$ Such guidance may also inform patient-centred outcome assessment in routine practice and registries, informing more targeted treatment and allocation of resources for survivors of cardiac arrest. ${ }^{54-58}$

Ethically, we cannot ignore the patient perspective. However, ensuring that patient-centred outcomes are captured to the best effect requires an improved understanding of what matters, for whom, in what context and when: this requires a further commitment to work together with the public, with the survivors of cardiac arrest and their families as partners in this process. ${ }^{59}$

\section{Practical implications for in- and out-of-hospital cardiac arrest}

\section{Outcome from sudden cardiac arrest}

Resuscitation attempts are unsuccessful in 70-98\% of cases. In pre-hospital systems with a well-organised implementation of the elements of the 'formula of survival' 20 about $1 / 3-1 / 2$ of patients may achieve return of spontaneous circulation (ROSC) with CPR, with a smaller proportion surviving to the hospital critical care unit. Smaller proportions still survive to hospital discharge with good neurological outcome. ${ }^{8}$

The best resuscitation outcome is for an individual to be cognitively unimpaired and with an acceptable quality of life, or to report no significant deterioration when compared to the pre-morbid state.

However, studies have reported cognitive impairment in up to $50 \%$ of survivors. ${ }^{9,60,61}$ Moreover, where acceptable levels of quality of life have been reported, this has been assessed using generic, preference-based utility measures such as the EuroQoL EQ-5D or Health Utility Index, or generic health status measures such as the Short Form 12-item Health Survey (SF-12). ${ }^{57,62,63}$ Whilst providing a broad overview of health status and a useful comparator with the general population, generic measures cannot capture the complexities of specific conditions and it is unclear if they accurately assess the outcomes that really matter to the CA survivors. ${ }^{55}$ Consequently, they may underestimate the health needs and experiences of survivors, and are often less responsive to important changes in recovery than well-developed condition or domain specific measures. ${ }^{55}$

Early adequate CPR may increase survival beyond 50\%. ${ }^{64,65}$ Substantial variation in survival is seen between communities. ${ }^{66-69}$ Real improvements in global outcome will require a communitycentred 'public health' approach. 8,70 Policy-level executives need to become aware of their crucial role in this.

\section{In-hospital cardiac arrest (IHCA)}

Following in-hospital cardiac arrest, the default position is to start resuscitation unless a decision was made to withhold CPR 
Decisions to withhold resuscitation are usually taken by a senior physician in collaboration with members of the multi-professional team. ${ }^{71}$ Resuscitation decisions should be reviewed following an emergency admission to hospital, after any important changes in patient status / prognosis, following a request from the patient or their relatives, and prior to discharge / transfer to another facility. ${ }^{72}$ Standardised systems to withhold resuscitation decrease the incidence of futile resuscitation attempts. ${ }^{72}$ Instructions should be specific, detailed, and transferable across health care settings, and easily understood. ${ }^{73,74}$ There may be occasions where a clinician decides it is necessary to override a prior decision to withhold CPR. Such circumstances might include a sudden arrest due to a readily reversible cause (e.g., choking, blocked tracheal tube) or where a patient is undergoing a specific procedure or general anaesthesia. Whenever possible such circumstances should be discussed in advance with the patient to establish their prior wishes.

Determining when CPR is likely to be unsuccessful or, in other words, futile, is often difficult. Two clinical decision rules have been developed using data from the AHA Get with the Guidelines Programme ( $n>50,000$ cases). The first developed a flow chart indicating the likelihood of survival to discharge with good neurological function. In this model, admission from a nursing facility with a cerebral performance category (CPC) of 2 or less had a very low (2.3\%) chance of survival after cardiac arrest, as did admission from home or another hospital and a CPC score of 3 (2.2\% survival). ${ }^{75}$ Other important predictors of poor outcome were advancing age, presence of organ failure, malignancy and hypotension. Absence of co-morbidities, presence of arrhythmias and myocardial infarction were associated with better outcomes. The Go-FAR score, produced by the same group uses 13 pre-arrest variables to predict outcome. ${ }^{75}$ A low score predicted good outcome (27\% favourable survival) whilst a high score predicted poor outcome ( $0.8 \%$ favourable survival). Good neurological function at admission predicted good outcome whilst major trauma, stroke, malignancy, sepsis, non-cardiac medical admission, organ failure and advancing age were key determinants of adverse outcomes. Prediction studies are particularly dependent on system factors such as time to start of CPR and time to defibrillation. These intervals may be prolonged in the total study cohort but may not be applicable to an individual case.

Inevitably, judgements will have to be made based on all available information. Decisions should not be made based on a single element, such as age. ${ }^{76}$ There will remain grey areas where judgement is required for individual patients.

It is difficult to define an optimal duration for resuscitation attempts. In a further study from the AHA Get With The GuidelinesResuscitation (GWTG-R) registry, 88\% of patients who achieved sustained ROSC did so within $30 \mathrm{~min} .{ }^{77}$ As a rule, resuscitation should be continued as long as VF persists. Asystole for more than 20 min during ALS in the absence of a reversible cause is generally accepted as an indication to abandon further resuscitation attempts. However, there are reports of exceptional cases that do not support the general rule, and each case must be assessed individually.

Presently, there are no valid prognostication tools of poor outcome during the first few hours after ROSC. The prediction of final neurological outcome in CA patients remaining comatose after ROSC is generally unreliable during the first 3 days after CA and until the first 2-3 days after termination of hypothermia.

Reliable prognostication of a poor outcome in comatose cardiac arrest survivors supports discussions with relatives and decisions to withdraw life-sustaining therapy. Guidelines for prognostication in such patients are described in detail in the post resuscitation care chapter of the 2015 ERC Guidelines. ${ }^{27}$

We should bear in mind that the implementation of a termination of resuscitation (ToR) protocol will inevitably introduce some self-fulfilling prophecy and must be challenged periodically as new treatments evolve.

The focus of most published studies has been on predicting poor outcomes amongst comatose survivors of cardiac arrest. Future research should also consider factors that would predict a good outcome in order to inform treatment decisions and discussions with relatives.

\section{Out-of-hospital cardiac arrest (OHCA)}

The decision to start or discontinue CPR is usually more challenging outside a hospital. ${ }^{78,79}$ Specific challenges include the lack of sufficient, unequivocal information about a patient's wishes and values, comorbidities and baseline health status. Access to diagnostic tests to identify reversible causes is limited and teams in general are small and in many countries only comprise emergency medical technicians or paramedics. Prognostic assessment in terms of survival and subsequent quality of life carries a higher risk of bias and thus injustice. ${ }^{80,81}$ Considering this and the proven correlation between time to BLS or first shock and outcome, the default for OHCA still needs to be to start CPR as soon as possible and address questions later. Exceptions are the conditions that enable recognition of life extinct (ROLE), namely massive cranial and cerebral destruction, decapitation, decomposition or putrefaction, incineration, dependent lividity (hypostasis) with rigor mortis, and foetal maceration. In such cases, the non-physician might be making a diagnosis of death but is not certifying death, which, in most countries, can be done only by a physician.

CPR that has no chance of success in terms of survival or acceptable quality of life is pointless and may violate the right for mercy and dignity in the face of death. Defining this 'no chance of success' is however very difficult and, in contrast to other medical interventions, it has been argued that success rates of less than $1 \%$ still justify the resuscitation effort. ${ }^{78,81,82}$ Institutional guidelines for the Termination Of Resuscitation (ToR) in the pre-hospital environment are very much needed to reduce unwanted variability in this decision-making.

Several authors have developed and prospectively tested unequivocal termination of resuscitation (ToR) rules. One prospective study demonstrated that a basic life support ToR rule was $100 \%$ predictive of death when applied by defibrillation-only emergency medical technicians. Subsequent studies showed external generalisability of this rule, but others challenged this. The implementation of a ToR rule significantly reduced the rate of transport of futile OHCA yet also led in two separate studies to an unexpected survival of $3.4 \%$ and $9 \%$ respectively in OHCA patients without pre-hospital sustained ROSC.

Some EMS systems use just that one component, the absence of pre-hospital return of spontaneous circulation (ROSC), as the criterion to terminate resuscitation and this clearly may exclude potential survivors for transportation. ${ }^{78,83-87}$

Patients with refractory cardiac arrest, with ongoing CPR during transport to hospital, used to have a very poor prognosis. ${ }^{88,89}$ In a moving vehicle, manual CPR may be difficult and the use of mechanical devices may be considered. As advanced rescue therapies and specific circumstances-related interventions become more widely available and success rates are improving, defining which patients might benefit from these becomes crucial. ${ }^{90-92}$

\section{Withholding or withdrawing CPR}

Healthcare professionals should consider withholding or withdrawing CPR in children and adults when:

- the safety of the provider can no longer be sufficiently assured; - there is obvious mortal injury or irreversible death [ROLE]; 
- a valid and relevant advance directive becomes available;

- there is other strong evidence that further CPR would be against patient's values and preferences or is considered 'futile';

- asystole for more than 20 min despite ongoing ALS, in the absence of a reversible cause.

After stopping CPR, the possibility of ongoing support of the circulation and transport to a dedicated centre in perspective of organ donation should be considered.

\section{Transport to hospital with ongoing $C P R$}

Healthcare professionals should consider transport to hospital with ongoing CPR when, in the absence of the above CPR withdrawal criteria, there is one or more of the following present:

- EMS witnessed arrest;

- ROSC at any moment;

- VT/VF as presenting rhythm;

- Presumed reversible cause (e.g., cardiac, toxic, hypothermia).

This decision should be considered early in the process e.g., after 10 min of ALS without ROSC and in view of the circumstances e.g., distance, CPR delay and presumed CPR quality in view of patient characteristics e.g., presumed QoL.

\section{Paediatric cardiac arrest}

Despite differences in pathophysiology and aetiology, the ethical framework for decision-making in paediatric cardiac arrest does not differ much from that described above. ${ }^{93,94}$ Most physicians will err even more on the side of intervention in children for emotional reasons and continue a resuscitation attempt longer, despite the overall prognosis in children often being worse than in adults. It is therefore important for clinicians to understand the factors that influence resuscitation success and the boundaries of the care they provide. As in adult practice, futile resuscitation might be considered dysthanasia (merciless prolongation of life) and should be avoided. ${ }^{81}$ The child's best interest might sometimes conflict with parent or guardian's rights. From a societal perspective, we allow parent's decisions to differ from so-called best interest standards as long as no unacceptable harm is done to the child. Extrapolating this to the context of resuscitation, parent's rights and decisionmaking might prevail up to the point where there would be harm. Prolonged futile resuscitation could be an example of such harm. Providing adequate information in a clear but empathic way is crucial for this decision-making process.

Most countries have procedures for medico-legal investigation of Sudden Unexplained Death Of Infancy (SUDI). In many SUDI cases no final cause is identified and death might be related to an intrinsic vulnerability, developmental changes and environmental factors. ${ }^{95}$ Some deaths however might be caused by infection, neuro-metabolic disease or by accidental or inflicted injury. In most countries, legal authorities are involved in cases of sudden unexplained or accidental death. In some countries systematic review of all child deaths is organised to get a better understanding and knowledge for the prevention of future children's deaths. ${ }^{96}$ Although there are still major challenges, formal child death reviews may contribute greatly to prevention, care delivered and final outcome of paediatric cardiac arrest.

\section{Specific circumstances}

Slow code

Some prehospital providers find it difficult to stop resuscitation once started and would argue for continuing CPR, especially in young persons, until arrival to the hospital. Some defend this practice on the ground that, at a certain point, the 'best interest' of the family might start to outweigh that of the patient. ${ }^{97,98}$ This view is not supported by evidence. In the setting of post-traumatic cardiac arrest it seemed that families of patients who die out-ofhospital adapt better to their losses when there is cessation of futile resuscitative efforts in the field. ${ }^{93}$ Performing futile CPR to address the grief and needs of 'significant others' is ethically unsound, being both deceptive and paternalistic. ${ }^{43}$

Likewise, certain authors argued in favour of a 'slow code' initiating some 'symbolic' resuscitation measures but unhurriedly or omitting the most aggressive ones, sparing physician and family the helpless feeling of doing nothing and avoiding potential conflict or the need to communicate bad news, especially in those settings where there is no strong physician-patient relationship and a clear lack of information. ${ }^{43}$ This 'slow code' is equally deceptive and paternalistic, and undermines both the patient-physician relationship and the training and education of our teams. ${ }^{93}$

A valuable alternative may be a 'tailored code', where high quality resuscitation is performed but clear limits are defined. Family members are informed in a transparent way what will be done and what not. ${ }^{99,100}$

\section{Provider safety}

Safety of the healthcare provider is vitally important. Infectious disease epidemics have raised concerns about the safety of healthcare providers involved in the care of cardiac arrest patients. Specific attention to the use of proper protective equipment is essential, especially when there is insufficient information about a patient's history and potential infectious state. To date there is little information about the precise risk of transmission when doing CPR on an infectious patient, and as such - if properly protected providers should attempt resuscitation in these patients. Possible exemptions to this standard rule would be those infections or situations where a clear danger remains for the healthcare provider, even when protected. In these cases the provider's own safety would be priority. When attempting CPR in infectious patients' healthcare professionals must use proper protective equipment and be sufficiently trained in its use. ${ }^{101,102}$

\section{Resuscitation after suicide attempts}

A person with mental illness is not necessarily considered mentally incompetent and may have an equal right to reject medical treatment and opt for palliative care. Based on the concept of autonomy, one could argue that a suicide attempt may in itself be an expression of personal preferences. In an emergency it is difficult to assess mental capacity reliably even if a suicide note is found. Given that non-treatment leads to serious harm, the default remains to start CPR as soon as possible and address potential issues later. ${ }^{103,104}$

\section{Organ donation}

The primary goal of resuscitation is to save the patient's life. ${ }^{105}$ Nonetheless, resuscitation efforts may result in brain death. In these cases, the aim of resuscitation could change to the preservation of organs for possible donation. ${ }^{106}$ Several studies have shown that the outcome of organs transplanted from patients who received CPR and are brain dead is not different from the outcomes of organs transplanted from patients who have been pronounced brain dead from other causes (see section on Post Resuscitation Care). ${ }^{107-109}$ However, the duty of resuscitation teams for the living patient should not be confused with the duty of physicians for the dead donors, where the organs are preserved to save other people's lives. On the other hand, it is reasonable to suggest that all European countries should enhance their efforts to maximise the possibility of organ donation from cardiac arrest patients who became brain 
dead or after stopping resuscitation in case of CPR failure. ${ }^{110}$ Procedures should ensure that any possible interference of the transplant team in the decision making of the resuscitation team is avoided.

\section{Variability in ethical CPR practices in Europe}

Ten years after a report by Baskett and Lim, ${ }^{111}$ opinion leaders representing 32 European countries where the activities of the European Resuscitation Council are organised, have responded to questions regarding local ethical legislation and practice of resuscitation, and organisation of out-of-hospital and in-hospital resuscitation services. The survey methods and results are detailed and discussed elsewhere.

The survey showed that there is still a wide variability in the implementation of ethical practices in European countries.

Equal access to emergency care and to early defibrillation is now well established: the first attending ambulance arrives at the scene within $10 \mathrm{~min}$ in the majority of countries (18/32 in rural areas and $24 / 32$ in urban areas). Defibrillation by the first attending ambulance is available in $29 / 32$ countries.

The principle of patient autonomy is now legally supported in the majority of countries (advance directives in 20 countries and DNAR in 22 countries).

However, areas for improvement were identified: in less than half of countries family members are usually allowed to be present during CPR (adult in 10/32 and children in 13/32 countries). This has not substantially changed in the last 10 years.

At this time euthanasia and physician-assisted suicide are controversial subjects in many European countries and the discussion is ongoing in several European countries.

Certain forms of treatment limitations such as withholding CPR are allowed (19 countries) and practiced (21 countries) in most European countries.

Harmonisation of legislation relating to resuscitation and endof-life would further support ethical practices.

Healthcare professionals should know and apply the established national and local legislation and policies.

\section{Communication}

\section{Family presence during resuscitation}

Since the 1980s, the concept of a family member being present at the resuscitation process became an accepted practice in many countries. ${ }^{112-116}$ The majority of relatives and parents who were present during resuscitation attempts would wish to be so again. ${ }^{113}$ A recent European survey reported that in only $31 \%$ of countries family members are usually allowed to be present during inhospital resuscitation attempts of an adult and only slightly more if the victim was a child (41\%).

The ERC supports relatives being offered the choice to be present during a resuscitation attempt whilst cultural and social variations must be understood and appreciated with sensitivity. Observing the resuscitation attempt may provide benefit to family members by reducing guilt or disappointment, allowing time to accept the reality of death and help the grieving process. When possible, an experienced member of staff should facilitate and support the relative during the resuscitation attempt. ${ }^{114,115}$ Family presence during resuscitation attempts will contribute to an increasingly open attitude and appreciation of the autonomy of both patient and relatives. ${ }^{111,112}$ No data support the concerns that family members may be traumatised witnessing CPR, or may interfere with medical care procedures. ${ }^{117}$ We should focus our efforts on working together with the survivors of cardiac arrest, family members and the public as partners in the co-production of future guidance.

\section{Bringing bad news and bereavement counselling}

A multidisciplinary approach to the care at the end of life, including communication, taking into account cultural, social, emotional, religious, spiritual preferences and local differences needs further development and implementation in healthcare systems worldwide.

Compassionate communication with patients and loved ones is essential when dealing with end of-life-care. The aim is to understand the patient's goals and expectations of medical treatment to support the individual choice of the best care. Some patients wish to prolong life as long as possible, while others value dignity and pain relief even at the expense of a potentially shortened lifetime. Privacy and adequate time are essential for good communication about life values and significant decisions. ${ }^{118}$

Multidisciplinary bereavement programs are beneficial to families of patients who die in the emergency department. ${ }^{119}$ The grieving process may be supported by allowing unrestricted visiting, provision of clear verbal and written information, providing the opportunity to visit the deceased and facilitating religious procedures. ${ }^{120,121}$ Patients and their beloved ones deserve respect.

Clinicians should be honest about what can and cannot be achieved. Sharing the truth of the situation can act as a symbolic expression of a complex set of commitments. ${ }^{29}$ This will allow the patients to make informed decisions about the choices available to them at the end of their lives.

\section{Documentation of DNAR order in the patient's chart}

DNAR decisions and discussions relating to DNAR should be recorded clearly in the patient's notes. ${ }^{72,73,122,123}$ Whatever system is used it must be highly visible in order to inform personnel on the spot.

Over time the situation or the perspectives of patients might change and DNAR orders should be revised accordingly. ${ }^{124}$ Exemptions from DNAR order should be clearly specified (e.g., cardiac arrest complicating diagnostic procedures, such as allergic shock due to radiology dye or intracardiac catheter investigation) to ensure the patient will receive appropriate treatment.

\section{Training, research and audit}

It is the individual responsibility of healthcare professionals to maintain their knowledge, understanding and skills related to resuscitation. Their knowledge about relevant national legal and organisational policies in their country should be kept up to date.

\section{Improving public education regarding Cardiopulmonary Resuscitation}

The shift from medical-centred to patient-centred practice constitutes a major ethical development. This requires that the patient is aware (and not misinformed) of the true limitations and possible outcomes of resuscitation. ${ }^{125-127}$ Lay people may have unrealistic expectations from $\mathrm{CPR}^{128,129}$ and exposure to realistic outcome data may affect personal preferences. ${ }^{130}$

\section{Training health care professionals about DNAR issues}

Healthcare professionals should receive training about the legal and ethical basis of DNAR decisions and about how to communicate effectively with patients, relatives or next of kin. Quality of life, supportive care and end-of-life decisions need to be explained as an integrative part of the medical and nursing practice. ${ }^{131}$ Training 
will need to be sensitive to personal, moral and religious beliefs and feelings.

\section{Practicing procedures on the recently dead}

There is a wide diversity of opinion about practicing on the newly dead ranging from complete non-acceptance because of an innate respect for the deceased ${ }^{132}$ to the acceptance of noninvasive procedures not leaving major marks. ${ }^{133}$ Others accept training of any procedure on dead bodies and justify skills training as paramount for the well-being of future patients. ${ }^{134-137}$

Healthcare students and teaching professionals are advised to learn and follow the established legal, regional and local hospital policies.

\section{Research and informed consent}

Research in the field of resuscitation is necessary to test commonly used interventions with uncertain efficacy or new potentially beneficial treatments. ${ }^{138,139}$ To include participants in a study, informed consent must be obtained. In emergencies, there is often insufficient time to obtain informed consent. Deferred consent or exception to informed consent with prior community consultation, are considered ethically acceptable alternatives for respecting autonomy. ${ }^{140,141}$ Following 12 years of ambiguity, a new European Union (EU) Regulation permitting deferred consent is expected to harmonise and foster emergency research across Member States. ${ }^{139,140,142,143}$ Further regulatory improvements are needed for emergency surgical research 144 and for researching non-medicinal interventions. ${ }^{139}$ Despite this progress, regulations still need to converge at an international level to harmonise multinational emergency research. ${ }^{145}$

\section{Audit of in-hospital cardiac arrests and registry analyses}

Local CPR management can be improved through post-CPR debriefing and feedback to ensure a PDCA (plan-do-checkact) circle of quality improvement. Debriefing and feedback enables identification of CPR quality errors and prevents their repetition. ${ }^{146-148}$ Submission of CPR data to national audits and/or international registries has led to outcome-prediction models, which may facilitate advance care planning ${ }^{149-153}$, and to quantification of the frequency of resuscitation system errors and their impact on in-hospital mortality. ${ }^{154}$ Data from registries have shown significant improvements in cardiac arrest outcomes from 2000 to $2010.3,155-157$

Published evidence suggests that resuscitation team-based infrastructure and multilevel institutional audit, 158 accurate reporting ${ }^{54}$ of resuscitation attempts at national audit level and/or multinational registry level, and subsequent data analysis and feedback from reported results may contribute to continuous improvement of in-hospital CPR quality and cardiac arrest outcomes. ${ }^{2,3,159-161}$

\section{Collaborators}

Marios Georgiou, American Medical Center, University of Nikosia, Cyprus

Freddy K. Lippert, Emergency Medical Services Copenhagen, University of Copenhagen, Denmark

Petter A. Steen, University of Oslo, Oslo University Hospital Ulleval, Oslo, Norway.

\section{Conflicts of interest}

Leo L. Bossaert

Gavin D. Perkins

Helen Askitopoulou

Jerry P. Nolan

Kirstie L. Haywood

Patrick Van de Voorde

Robert Greif

Violetta I. Raffay

Theodoros T. Xanthos
Spyros D. Mentzelopoulos
No conflict of interest reported Editor Resuscitation No conflict of interest reported Editor-in-Chief Resuscitation No conflict of interest reported No conflict of interest reported No conflict of interest reported No conflict of interest reported No conflict of interest reported President Hellenic Society CPR www.EEKA.gr, Lab research grants ELPEN Pharma

\section{Acknowledgements}

The authors thank Hilary Phelan for her professional support in preparing the on-line questionnaire for the European Survey on Ethical Practices and for organising the data in a dedicated database.

The authors thank all contributors to the European Survey on Ethical Practices: M. Baubin, A. Caballero, P. Cassan, G. Cebula, A. Certug, D. Cimpoesu, S. Denereaz, C. Dioszeghy, M. Filipovic, Z. Fiser, M. Georgiou, E. Gomez, P. Gradisel, JT. Gräsner, R. Greif, H. Havic, S. Hoppu, S. Hunyadi, M. Ioannides, J. Andres, J. Joslin, D. Kiss, J. Köppl, P. Krawczyk, K. Lexow, F. Lippert, S. Mentzelopoulos, P. Mols, N. Mpotos, P. Mraz, V. Nedelkovska, H. Oddsson, D. Pitcher, V. Raffay, P. Stammet, F. Semeraro, A. Truhlar, H. Van Schuppen, D. Vlahovic, A. Wagner.

\section{References}

1. Berdowski J, Berg RA, Tijssen JG, Koster RW. Global incidences of out-ofhospital cardiac arrest and survival rates: systematic review of 67 prospective studies. Resuscitation 2010;81:1479-87.

2. McNally B, Robb R, Mehta M, et al. Out-of-hospital cardiac arrest surveillance-cardiac arrest registry to enhance survival (CARES), 60. United States: MMWR Surveillance Summaries; 2011. p. 1-19.

3. Daya MR, Schmicker RH, Zive DM, et al. Out-of-hospital cardiac arrest survival improving over time: results from the resuscitation outcomes consortium (ROC). Resuscitation 2015;91:108-15.

4. Sasson C, Rogers MA, Dahl J, Kellermann AL. Predictors of survival from out-ofhospital cardiac arrest: a systematic review and meta-analysis. Circ Cardiovasc Oual Outcomes 2010;3:63-81.

5. Kolte D, Khera S, Aronow WS, et al. Regional variation in the incidence and outcomes of in-hospital cardiac arrest in the United States. Circulation 2015; $131: 1415-25$

6. Nichols M, Townsend N, Scarborough P, Rayner M. Cardiovascular disease in Europe: epidemiological update. Eur Heart J 2013;34:3028-34.

7. Mozaffarian D, Benjamin EJ, Go AS, et al. Heart disease and stroke statistics-2015 update: a report from the American Heart Association. Circulation 2015;131:e29-322.

8. Wissenberg M, Lippert FK, Folke F, et al. Association of national initiatives to improve cardiac arrest management with rates of bystander intervention and patient survival after out-of-hospital cardiac arrest. JAMA 2013:310:1377-84.

9. Holler NG, Mantoni T, Nielsen SL, Lippert F, Rasmussen LS. Long-term survival after out-of-hospital cardiac arrest. Resuscitation 2007;75:23-8.

11. Beauchamp TL, Childress JF. Principles of biomedical ethics. 6th ed. New York: Oxford University Press; 2009.

12. English V, Sommerville A. Medical ethics today: the BMA's handbook of ethics and law. 2nd ed. London: BMJ Books; 2004

13. Marco CA, Marco CA. Ethical issues of resuscitation: an American perspective. Postgrad Med J 2005;81:608-12.

14. Kaldjian LC, Weir RF, Duffy TP. A clinician's approach to clinical ethical reasoning. J Gen Intern Med 2005;20:306-11.

15. O'Neill O. Autonomy and trust in bioethics. Cambridge, New York: Cambridge University Press; 2002

16. World Medical Association. Medical ethics manual. second edn Ferney-Voltaire Cedex: The World Medical Association; 2009.

17. Rysavy M. Evidence-based medicine: a science of uncertainty and an art of probability. Virtual Mentor 2013;15:4-8.

18. Christine PJ, Kaldjian LC. Communicating evidence in shared decision making. Virtual Mentor 2013;15:9-17.

19. Council of Europe. Biomedicine human rights-the Oviedo convention its additional protocols. Strasbourg: Council of Europe; 2010 
20. Soreide E, Morrison L, Hillman K, et al. The formula for survival in resuscitation. Resuscitation 2013;84:1487-93.

21. Lippert FK, Raffay V, Georgiou M, Steen PA, Bossaert L. European Resuscitation Council guidelines for resuscitation 2010 Section 10 . The ethics of resuscitation and end-of-life decisions. Resuscitation 2010;81:1445-51.

22. Morrison LJ, Kierzek G, Diekema DS, et al. Part 3: ethics: 2010 American heart association guidelines for cardiopulmonary resuscitation and emergency cardiovascular care. Circulation 2010;122:S665-75.

23. National Institute for Health and Clinical Excellence. How NICE clinical guidelines are developed: an overview for stakeholders, the public and the NHS. In: Process and Methods Guides. 5th edition London: National Institute for Health and Clinical Excellence; 2012.

24. Brody BA, Halevy A. Is futility a futile concept? J Med Philos 1995;20:123-44.

25. Swig L, Cooke M, Osmond D, et al. Physician responses to a hospital policy allowing them to not offer cardiopulmonary resuscitation. J Am Geriatr Soc 1996;44:1215-9.

26. Truog RD, Brett AS, Frader J. The problem with futility. N Engl J Med 1992:326:1560-4.

27. Sandroni C, Cariou A, Cavallaro F, et al. Prognostication in comatose survivors of cardiac arrest: an advisory statement from the European Resuscitation Council and the European Society of Intensive Care Medicine. Resuscitation 2014;85:1779-89.

28. Frader J, Kodish E, Lantos JD. Ethics rounds. Symbolic resuscitation, medical futility, and parental rights. Pediatrics 2010;126:769-72.

29. Lantos JD, Meadow WL. Should the "slow code" be resuscitated? Am J Bioethics 2011:11:8-12.

30. Chu K, Swor R, Jackson R, et al. Race and survival after out-of-hospital cardiac arrest in a suburban community. Ann Emerg Med 1998;31:478-82.

31. Vaillancourt C, Lui A, De Maio VJ, Wells GA, Stiell IG. Socioeconomic status influences bystander CPR and survival rates for out-of-hospital cardiac arrest victims. Resuscitation 2008;79:417-23.

32. Folke F, Gislason GH, Lippert FK, et al. Differences between out-of-hospital cardiac arrest in residential and public locations and implications for publicaccess defibrillation. Circulation 2010;122:623-30.

33. Ahn KO, Shin SD, Hwang SS, et al. Association between deprivation status at community level and outcomes from out-of-hospital cardiac arrest: a nationwide observational study. Resuscitation 2011;82:270-6.

34. Aufderheide TP, Nolan JP, Jacobs IG, et al. Global health and emergency care: a resuscitation research agenda-part 1. Acad Emerg Med 2013;20:1289-96.

35. Sasson C, Magid DJ, Chan P, et al. Association of neighborhood characteristics with bystander-initiated CPR. N Engl J Med 2012;367:1607-15.

36. Semple HM, Cudnik MT, Sayre M, et al. Identification of high-risk communities for unattended out-of-hospital cardiac arrests using GIS. J Community Health 2013;38:277-84.

37. Rahimi AR, Spertus JA, Reid KJ, Bernheim SM, Krumholz HM. Financial barriers to health care and outcomes after acute myocardial infarction. JAMA 2007;297:1063-72

38. Root ED, Gonzales L, Persse DE, Hinchey PR, McNally B, Sasson C. A tale of two cities: the role of neighborhood socioeconomic status in spatial clustering of bystander CPR in Austin and Houston. Resuscitation 2013;84:752-9.

39. Yusuf S, Rangarajan S, Teo K, et al. Cardiovascular risk and events in 17 low-, middle-, and high-income countries. N Engl J Med 2014;371:818-27.

40. Waisel DB, Truog RD. The cardiopulmonary resuscitation-not-indicated order: futility revisited. Ann Intern Med 1995;122:304-8.

41. British Medical Association, The Resuscitation Council (UK), The Royal College of Nursing. Decisions relating to cardiopulmonary resuscitation. A joint statment from the British Medical Association, the Resuscitation Council (UK) and the Royal College of Nursing. London: British Medical Association; 2014.

42. Soholm H, Bro-Jeppesen J, Lippert FK, et al. Resuscitation of patients suffering from sudden cardiac arrests in nursing homes is not futile. Resuscitation 2014;85:369-75.

43. Bremer A, Sandman L. Futile cardiopulmonary resuscitation for the benefit of others: an ethical analysis. Nurs Ethics 2011;18:495-504.

44. Committee on Bioethics (DH-BIO) of the Council of and Europe. Guide on the decision-making process regarding medical treatment in end-of-life situations. Strasbourg: Council of Europe; 2014.

45. Fritz Z, Cork N, Dodd A, Malyon A. DNACPR decisions: challenging and changing practice in the wake of the Tracey judgment. Clin Med 2014;14:571-6.

46. Etheridge Z, Gatland E. When and how to discuss "do not resuscitate" decisions with patients. BMJ 2015;350:h2640.

47. Blinderman CD, Krakauer EL, Solomon MZ. Time to revise the approach to determining cardiopulmonary resuscitation status. JAMA 2012;307:917-8

48. Xanthos T. 'Do not attempt cardiopulmonary resuscitation' or 'allowing natural death'? The time for resuscitation community to review its boundaries and its terminology. Resuscitation 2014;85:1644-5.

49. Salkic A, Zwick A. Acronyms of dying versus patient autonomy. Eur J Health Law 2012;19:289-303.

50. Johnston C, Liddle J. The Mental Capacity Act 2005: a new framework for healthcare decision making. J Med Ethics 2007;33:94-7.

51. Andorno R, Biller-Andorno N, Brauer S. Advance health care directives: towards a coordinated European policy? Eur J Health Law 2009;16:207-27.

52. Shaw D. A direct advance on advance directives. Bioethics 2012;26:267-74.

53. Resuscitation Council (UK). Quality Standards for cardiopulmonary resuscitation practice and training. Acute care. London, UK: Resuscitation Council; 2013.
54. Perkins GD, Jacobs IG, Nadkarni VM, et al. Cardiac arrest and cardiopulmonary resuscitation outcome reports: update of the Utstein resuscitation registry templates for out-of-hospital cardiac arrest. Resuscitation 2015;96: 328-40.

55. Haywood KL, Whitehead L, Perkins GD. The psychosocial outcomes of cardiac arrest: relevant and robust patient-centred assessment is essential. Resuscitation 2014:85:718-9.

56. Whitehead L, Perkins GD, Clarey A, Haywood KL. A systematic review of the outcomes reported in cardiac arrest clinical trials: the need for a core outcome set. Resuscitation 2015;88:150-7.

57. Beesems SG, Wittebrood KM, de Haan RJ, Koster RW. Cognitive function and quality of life after successful resuscitation from cardiac arrest. Resuscitation 2014;85:1269-74

58. Moulaert VRMP, Verbunt JA, van Heugten CM, Wade DT. Cognitive impairments in survivors of out-of-hospital cardiac arrest: a systematic review. Resuscitation 2009;80:297-305.

59. Staniszewska S, Haywood KL, Brett J, Tutton L. Patient and public involvement in patient-reported outcome measures: evolution not revolution. Patient 2012;5:79-87.

60. Lilja G, Nielsen N, Friberg H, et al. Cognitive function in survivors of out-ofhospital cardiac arrest after target temperature management at $33^{\circ} \mathrm{C}$ versus $36^{\circ} \mathrm{C}$. Circulation 2015;131:1340-9.

61. Wachelder EM, Moulaert VR, van Heugten C, Verbunt JA, Bekkers SC, Wade DT. Life after survival: long-term daily functioning and quality of life after an out-of-hospital cardiac arrest. Resuscitation 2009;80:517-22.

62. Smith K, Andrew E, Lijovic M, Nehme Z, Bernard S. Quality of life and functional outcomes 12 months after out-of-hospital cardiac arrest. Circulation 2015:131:174-81.

63. Kragholm K, Wissenberg M, Mortensen RN, et al. Return to work in out-ofhospital cardiac arrest survivors: a nationwide register-based follow-up study. Circulation 2015:131:1682-90.

64. Nakamura F, Hayashino Y, Nishiuchi T, et al. Contribution of out-of-hospital factors to a reduction in cardiac arrest mortality after witnessed ventricular fibrillation or tachycardia. Resuscitation 2013;84:747-51.

65. Meyer L, Stubbs B, Fahrenbruch C et al. Incidence, causes, and survival trends from cardiovascular-related sudden cardiac arrest in children and young adults 0 to 35 years of age: a 30-year review. Circulation 2012;126: 1363-72

66. Bardai A, Berdowski J, van der Werf C, et al. Incidence, causes, and outcomes of out-of-hospital cardiac arrest in children. A comprehensive, prospective, population-based study in the Netherlands. J Am Coll Cardiol 2011;57: 1822-8.

67. Perkins GD, Cooke MW. Variability in cardiac arrest survival: the NHS Ambulance Service Quality Indicators. Emerg Med J EMJ 2012;29:3-5.

68. Fothergill RT, Watson LR, Chamberlain D, Virdi GK, Moore FP, Whitbread M. Increases in survival from out-of-hospital cardiac arrest: a five year study. Resuscitation 2013;84:1089-92.

69. Hasegawa K, Hiraide A, Chang Y, Brown DF. Association of prehospital advanced airway management with neurologic outcome and survival in patients with out-of-hospital cardiac arrest. JAMA 2013;309:257-66.

70. Van de Voorde P, Monsieurs KG, Perkins GD, Castren M. Looking over the wall: using a Haddon matrix to guide public policy making on the problem of sudden cardiac arrest. Resuscitation 2014;85:602-5.

71. Mockford C, Fritz Z, George R, et al. Do not attempt cardiopulmonary resuscitation (DNACPR) orders: a systematic review of the barriers and facilitators of decision-making and implementation. Resuscitation 2015;88:99-113.

72. Field RA, Fritz Z, Baker A, Grove A, Perkins GD. Systematic review of interventions to improve appropriate use and outcomes associated with do-not-attempt-cardiopulmonary-resuscitation decisions. Resuscitation 2014;85:1418-31.

73. Freeman K, Field RA, Perkins GD. Variation in local trust do not attempt cardiopulmonary resuscitation (DNACPR) policies: a review of 48 english healthcare trusts. BMJ Open 2015;5:e006517.

74. Clements M, Fuld J, Fritz Z. Documentation of resuscitation decision-making: a survey of practice in the United Kingdom. Resuscitation 2014;85:606-11.

75. Ebell MH, Afonso AM, Geocadin RG. American heart association's get with the guidelines-resuscitation I. Prediction of survival to discharge following cardiopulmonary resuscitation using classification and regression trees. Crit Care Med 2013;41:2688-97.

76. Lannon R, O'Keeffe ST Cardiopulmonary resuscitation in older people-a review. Rev Clin Gerontol 2010;20:20-9.

77. Goldberger ZD, Chan PS, Berg RA, et al. Duration of resuscitation efforts and survival after in-hospital cardiac arrest: an observational study. Lancet 2012;380:1473-81.

78. Becker TK, Gausche-Hill M, Aswegan AL, et al. Ethical challenges in emergency medical services: controversies and recommendations. Prehosp Disaster Med 2013:28:488-97.

79. Nordby H, Nohr O. The ethics of resuscitation: how do paramedics experience ethical dilemmas when faced with cancer patients with cardiac arrest? Prehosp Disaster Med 2012:27:64-70.

80. Ranola PA, Merchant RM, Perman SM, et al. How long is long enough, and have we done everything we should? Ethics of calling codes. J Med Ethics 2014;41:663-6.

81. Mercurio MR, Murray PD, Gross I. Unilateral pediatric "do not attempt resuscitation" orders: the pros, the cons, and a proposed approach. Pediatrics 2014;133:S37-43 [Suppl 1]. 
82. Levinson M, Mills A. Cardiopulmonary resuscitation-time for a change in the paradigm? Med J Aust 2014;201:152-4.

83. Morrison LJ, Verbeek PR, Zhan C, Kiss A, Allan KS. Validation of a universal prehospital termination of resuscitation clinical prediction rule for advanced and basic life support providers. Resuscitation 2009;80:324-8.

84. Skrifvars MB, Vayrynen T, Kuisma M, et al. Comparison of Helsinki and European Resuscitation Council "do not attempt to resuscitate" guidelines, and a termination of resuscitation clinical prediction rule for out-of-hospital cardiac arrest patients found in asystole or pulseless electrical activity. Resuscitation 2010;81:679-84.

85. Diskin FJ, Camp-Rogers T, Peberdy MA, Ornato JP, Kurz MC. External validation of termination of resuscitation guidelines in the setting of intra-arrest cold saline, mechanical CPR, and comprehensive post resuscitation care. Resuscitation 2014;85:910-4.

86. Morrison LJ, Eby D, Veigas PV, et al. Implementation trial of the basic life support termination of resuscitation rule: reducing the transport of futile outof-hospital cardiac arrests. Resuscitation 2014;85:486-91.

87. Drennan IR, Lin S, Sidalak DE, Morrison LJ. Survival rates in out-of-hospital cardiac arrest patients transported without prehospital return of spontaneous circulation: an observational cohort study. Resuscitation 2014;85: 1488-93.

88. Kellermann AL, Hackman BB, Somes G. Predicting the outcome of unsuccessful prehospital advanced cardiac life support. JAMA 1993;270:1433-6.

89. Olasveengen TM, Wik L, Steen PA. Quality of cardiopulmonary resuscitation before and during transport in out-of-hospital cardiac arrest. Resuscitation 2008;76:185-90

90. Zive D, Koprowicz K, Schmidt T, et al. Variation in out-of-hospital cardiac arrest resuscitation and transport practices in the resuscitation outcomes consortium: ROC epistry-cardiac arrest. Resuscitation 2011;82:277-84.

91. Sasson C, Hegg AJ, Macy M, Park A, Kellermann A, McNally B. Prehospital termination of resuscitation in cases of refractory out-of-hospital cardiac arrest. JAMA 2008;300:1432-8.

92. Stub D, Bernard S, Pellegrino V, et al. Refractory cardiac arrest treated with mechanical CPR, hypothermia, ECMO and early reperfusion (the CHEER trial). Resuscitation 2015;86:88-94.

93. Fallat M, American College of Surgeons Committee, American College of Emergency Physicians, National Association of EMS, American Academy of Pediatrics. Withholding or termination of resuscitation in pediatric out-of-hospital traumatic cardiopulmonary arrest. Pediatrics 2014;133: e1104-16.

94. Larcher V, Craig F, Bhogal K, et al. Making decisions to limit treatment in lifelimiting and life-threatening conditions in children: a framework for practice. Arch Dis Child 2015;100:s3-23 [Suppl 2], Published Online First: 19 February 2015.

95. Fleming PJ, Blair PS, Pease A. Sudden unexpected death in infancy: aetiology, pathophysiology, epidemiology and prevention in 2015. Arch Dis Child 2015.

96. Fraser J, Sidebotham P, Frederick J, Covington T, Mitchell EA. Learning from child death review in the USA, England, Australia, and New Zealand. Lancet 2014;384:894-903.

97. Truog RD, Miller FG. Counterpoint: are donors after circulatory death really dead, and does it matter? No and not really. Chest 2010;138:16-8 [discussion 8-9].

98. Paris JJ, Angelos P, Schreiber MD. Does compassion for a family justify providing futile CPR? J Perinatol: Off J California Perinat Assoc 2010;30:770-2.

99. Sanders A, Schepp M, Baird M. Partial do-not-resuscitate orders: a hazard to patient safety and clinical outcomes? Crit Care Med 2011;39:14-8.

100. Forman EN, Ladd RE. Why not a slow code? Virtual Mentor 2012;14:759-62.

101. Ulrich CM, Grady C. Cardiopulmonary resuscitation for Ebola patients: ethical considerations. Nurs Outlook 2015;63:16-8.

102. Torabi-Parizi P, Davey Jr RT, Suffredini AF, Chertow DS. Ethical and practical considerations in providing critical care to patients with ebola virus disease. Chest 2015;147:1460-6.

103. David AS, Hotopf M, Moran P, Owen G, Szmukler G, Richardson G. Mentally disordered or lacking capacity? Lessons for management of serious deliberate self harm. BMJ 2010;341:c4489.

104. Sontheimer D. Suicide by advance directive? J Med Ethics 2008;34:e4.

105. Zavalkoff SR, Shemie SD. Cardiopulmonary resuscitation: saving life then saving organs? Crit Care Med 2013;41:2833-4.

106. Orioles A, Morrison WE, Rossano JW, et al. An under-recognized benefit of cardiopulmonary resuscitation: organ transplantation. Crit Care Med 2013;41:2794-9.

107. Ali AA, Lim E, Thanikachalam M, et al. Cardiac arrest in the organ donor does not negatively influence recipient survival after heart transplantation. Eur J Cardiothorac Surg 2007;31:929-33.

108. Matsumoto CS, Kaufman SS, Girlanda R, et al. Utilization of donors who have suffered cardiopulmonary arrest and resuscitation in intestinal transplantation. Transplantation 2008;86:941-6.

109. Dhital KK, Iyer A, Connellan M, et al. Adult heart transplantation with distant procurement and ex-vivo preservation of donor hearts after circulatory death: a case series. Lancet 2015;385:2585-91.

110. Gillett G. Honouring the donor: in death and in life. J Med Ethics 2013;39:149-52.

111. Baskett PJ, Lim A. The varying ethical attitudes towards resuscitation in Europe. Resuscitation 2004;62:267-73.

112. Doyle CJ, Post H, Burney RE, Maino J, Keefe M, Rhee KJ. Family participation during resuscitation: an option. Ann Emerg Med 1987;16:673-5.
113. Boie ET, Moore GP, Brummett C, Nelson DR. Do parents want to be present during invasive procedures performed on their children in the emergency department? A survey of 400 parents. Ann Emerg Med 1999;34:70-4.

114. Eichhorn DJ, Meyers T, Guzzetta CE, et al. Family presence during invasive procedures and resuscitation: hearing the voice of the patient. AJN Am J Nurs 2001;101:48-55.

115. Wagner JM. Lived experience of critically ill patients family members during cardiopulmonary resusitation. AJCC 2004;13:416-20.

116. Jabre P, Tazarourte K, Azoulay E, et al. Offering the opportunity for family to be present during cardiopulmonary resuscitation: 1-year assessment. Intensive Care Med 2014;40:981-7.

117. Robinson SM, Mackenzie-Ross S, Campbell Hewson GL, Egleston CV, Prevost AT. Psychological effect of witnessed resuscitation on bereaved relatives. Lancet 1998;352:614-7.

118. Fallowfield LJ, Jenkins VA, Beveridge HA. Truth may hurt but deceit hurts more: communication in palliative care. Palliat Med 2002;16:297-303.

119. LeBrocq P, Charles A, Chan T, Buchanan M. Establishing a bereavement program: caring for bereaved families and staff in the emergency department. Accid Emerg Nurs 2003;11:85-90.

120. Rabow MW, Hauser JM, Adams J. Supporting family caregivers at the end of life: “they don't know what they don't know". JAMA 2004;291:483-91.

121. Olsen JC, Buenefe ML, Falco WD. Death in the emergency department. Ann Emerg Med 1998;31:758-65.

122. Hurst SA, Becerra M, Perrier A, Perron NJ, Cochet S, Elger B. Including patients in resuscitation decisions in Switzerland: from doing more to doing better. J Med Ethics 2013;39:158-65.

123. Gorton AJ, Jayanthi NV, Lepping P, Scriven MW. Patients' attitudes towards "do not attempt resuscitation" status. J Med Ethics 2008;34:624-6.

124. Micallef S, Skrifvars MB, Parr MJ. Level of agreement on resuscitation decisions among hospital specialists and barriers to documenting do not attempt resuscitation (DNAR) orders in ward patients. Resuscitation 2011:82:815-8.

125. Horburger D, Haslinger J, Bickel H, et al. Where no guideline has gone before: retrospective analysis of resuscitation in the 24th century. Resuscitation 2014;85:1790-4.

126. Hinkelbein J, Spelten O, Marks J, Hellmich M, Bottiger BW, Wetsch WA An assessment of resuscitation quality in the television drama emergency room: guideline non-compliance and low-quality cardiopulmonary resuscitation lead to a favorable outcome? Resuscitation 2014;85:1106-10.

127. Diem SJ, Lantos JD, Tulsky JA. Cardiopulmonary resuscitation on television. Miracles and misinformation. N Engl J Med 1996;334:1578-82.

128. Roberts D, Hirschman D, Scheltema K. Adult and pediatric CPR: attitudes and expectations of health professionals and laypersons. Am J Emerg Med 2000; $18: 465-8$.

129. Jones GK, Brewer KL, Garrison HG. Public expectations of survival following cardiopulmonary resuscitation. Acad Emerg Med: Off J Soc Acad Emerg Med 2000; 7:48-53.

130. Marco CA, Larkin GL. Public education regarding resuscitation: effects of a multimedia intervention. Ann Emerg Med 2003;42:256-60.

131. Pitcher D, Smith G, Nolan J, Soar J. The death of DNR. Training is needed to dispel confusion around DNAR. BMJ 2009;338:b2021.

132. Bülow H-H, Sprung C, Reinhart K, et al. The world's major religions' points of view on end-of-life decisions in the intensive care unit. Intensive Care Med 2008;34:423-30.

133. Berger JT, Rosner F, Cassell EJ. Ethics of practicing medical procedures on newly dead and nearly dead patients. J Gen Intern Med 2002;17:774-8.

134. Morag RM, DeSouza S, Steen PA, et al. Performing procedures on the newly deceased for teaching purposes: what if we were to ask? Arch Intern Med 2005; 165:92-6.

135. Fourre MW. The performance of procedures on the recently deceased. Acad Emerg Med: Off J Soc Acad Emerg Med 2002;9:595-8.

136. Makowski AL. The ethics of using the recently deceased to instruct residents in cricothyrotomy. Ann Emerg Med 2015, http://dx.doi.org/10.1016/ j.annemergmed.2014.11.019, pii: S0196-0644(14)01560-1, [Epub ahead of print].

137. Hergenroeder GW, Prator BC, Chow AF, Powner DJ. Postmortem intubation training: patient and family opinion. Med Educ 2007;41:1210-6.

138. Davies H, Shakur H, Padkin A, Roberts I, Slowther AM, Perkins GD. Guide to the design and review of emergency research when it is proposed that consent and consultation be waived. Emerg Med J EMJ 2014;31:794-5.

139. Mentzelopoulos SD, Mantzanas M, van Belle G, Nichol G. Evolution of European Union legislation on emergency research. Resuscitation 2015;91:84-91.

140. Booth MG. Informed consent in emergency research: a contradiction in terms. Sci Eng Ethics 2007;13:351-9.

141. World Medical Association. Declaration of helsinki: ethical principles for medical research involving human subjects. JAMA 2013;310:2191-4.

142. Perkins GD, Bossaert L, Nolan J, et al. Proposed revisions to the EU clinical trials directive-comments from the European Resuscitation Council. Resuscitation 2013;84:263-4.

143. Lemaire F. Clinical research in the ICU: response to Kompanje et al. Intensive Care Med 2014;40:766.

144. Coats TJ. Barriers, regulations and solutions in emergency surgery research. $\mathrm{Br}$ J Surg 2014;101:e3-4.

145. van Belle G, Mentzelopoulos SD, Aufderheide T, May S, Nichol G. International variation in policies and practices related to informed consent in acute cardiovascular research: results from a 44 country survey. Resuscitation 2015;91:76-83. 
146. Edelson DP, Litzinger B, Arora V, et al. Improving in-hospital cardiac arrest process and outcomes with performance debriefing. Arch Intern Med 2008;168:1063-9.

147. McInnes AD, Sutton RM, Nishisaki A, et al. Ability of code leaders to recall CPR quality errors during the resuscitation of older children and adolescents. Resuscitation 2012;83:1462-6.

148. Wolfe $\mathrm{H}$, Zebuhr C, Topjian AA, et al. Interdisciplinary ICU cardiac arrest debriefing improves survival outcomes*. Crit Care Med 2014;42:1688-95.

149. Nolan JP, Soar J, Smith GB, et al. Incidence and outcome of in-hospital cardiac arrest in the United Kingdom national cardiac arrest audit. Resuscitation 2014;85:987-92.

150. Harrison DA, Patel K, Nixon E, et al. Development and validation of risk models to predict outcomes following in-hospital cardiac arrest attended by a hospitalbased resuscitation team. Resuscitation 2014;85:993-1000.

151. Chan PS, Berg RA, Spertus JA, et al. Risk-standardizing survival for inhospital cardiac arrest to facilitate hospital comparisons. J Am Coll Cardiol 2013;62:601-9.

152. Chan PS, Spertus JA, Krumholz HM, et al. A validated prediction tool for initial survivors of in-hospital cardiac arrest. Arch Intern Med 2012;172:947-53.

153. Larkin GL, Copes WS, Nathanson BH, Kaye W. Pre-resuscitation factors associated with mortality in 49,130 cases of in-hospital cardiac arrest: a report from the national registry for cardiopulmonary resuscitation. Resuscitation 2010;81:302-11.
154. Ornato JP, Peberdy MA, Reid RD, Feeser VR, Dhindsa HS. Impact of resuscitation system errors on survival from in-hospital cardiac arrest. Resuscitation 2012;83:63-9.

155. Girotra S, Nallamothu BK, Spertus JA, et al. Trends in survival after in-hospita cardiac arrest. N Engl J Med 2012;367:1912-20.

156. Girotra S, Cram P, Spertus JA, et al. Hospital variation in survival trends for in-hospital cardiac arrest. J Am Heart Assoc 2014;3:e000871.

157. Girotra S, Spertus JA, Li Y, et al. Survival trends in pediatric in-hospital cardiac arrests: an analysis from Get With the Guidelines-Resuscitation. Circ Cardiovasc Qual Outcomes 2013;6:42-9.

158. Gabbott D, Smith G, Mitchell S, et al. Cardiopulmonary resuscitation standards for clinical practice and training in the UK. Resuscitation 2005;64: 13-9.

159. Grasner IT, Herlitz J, Koster RW, Rosell-Ortiz F, Stamatakis L, Bossaert L. Quality management in resuscitation-towards a European cardiac arrest registry (EuReCa). Resuscitation 2011;82:989-94.

160. Grasner JT, Bossaert L. Epidemiology and management of cardiac arrest: what registries are revealing. Best Pract Res Clin Anaesthesiol 2013;27: 293-306.

161. Wnent J, Masterson S, Grasner JT, et al. EuReCa ONE-27 Nations, ONE Europe, ONE Registry: a prospective observational analysis over one month in 27 resuscitation registries in Europe-the EuReCa ONE study protocol. Scand J Trauma, Resuscitation Emerg Med 2015;23:7. 